\title{
Systolic pressure variation ( $\Delta$ down) can guide fluid therapy during pheochromocytoma surgery
}

\author{
[La variation de la pression systolique ( $\Delta$ down) peut guider le remplissage vascu- \\ laire pendant la résection d'un phéochromocytome]
}

Jihad Mallat MD, Andrei Pironkov MD, Marie-Sophie Destandau MD, Benoît Tavernier MD PhD

\begin{abstract}
Purpose: To date, no monitoring has proved its usefulness for both interpretation and treatment of arterial hypotension following pheochromocytoma resection. In this prospective observational study, we measured the negative component ( $\Delta$ down) of the respiratory systolic pressure variation in order to assess its ability to guide fluid therapy in 13 patients undergoing pheochromocytoma surgery.
\end{abstract}

Methods: The arterial pressure waveform was recorded via a 20$g$ radial artery catheter. $\Delta$ down was measured during abdominal exploration (baseline), after fluid loading, before and following tumour resection, and during treatment of arterial hypotension.

Results: At baseline, $\Delta$ down ranged between I and $15 \mathrm{mmHg}$ (median: $3 \mathrm{mmHg}$ ). Volume loading (500 mL colloid over $20 \mathrm{~min}$ ) performed during abdominal exploration significantly reduced $\Delta$ down $(P=0.00 \mathrm{I})$ and resulted in $\Delta$ down values $\leq 2 \mathrm{mmHg}$ in all 13 patients. The $\Delta$ down measured immediately before resection was larger in patients who had arterial hypotension (systolic arterial pressure (SAP) $<90 \mathrm{mmHg}$ ) following tumour removal than in other patients $[4(\mathrm{I}-10)$ vs $\mathrm{I}(0-3) \mathrm{mmHg} ; P=0.04]$. During hypotension, $\Delta$ down was greater in patients where fluid replacement restored SAP than in patients where fluids were ineffective and vasopressors needed $[\Delta$ down: 4 (3-9) vs I (I-2) $\mathrm{mmHg} ; P=0.03$.

Conclusion: During pheochromocytoma surgery, a $\Delta$ down $\leq 2$ $\mathrm{mmHg}$ appears to indicate minimal intravascular volume depletion. $\Delta$ down measurements could be used to guide fluid therapy for the prevention and treatment of arterial hypotension following pheochromocytoma removal.

Objectif : Aucun monitorage n'est encore utile à l'interprétation et au traitement de l'hypotension artérielle qui suit la résection d'un phéochromocytome. Pendant notre étude prospective par observation, nous avons mesuré la composante négative ( $\Delta$ down) de la variation de la pression systolique respiratoire afin d'évaluer sa capacité à guider le remplissage vasculaire chez 13 patients opérés pour un phéochromocytome.

Méthode : La pression artérielle a été enregistrée au moyen d'un cathéter artériel radial de calibre 20. Le $\Delta$ down a été mesuré pendant l'exploration abdominale (mesure de base), après la charge liquidienne, avant et après la résection tumorale et pendant le traitement de l'hypotension artérielle.

Résultats : Au départ, le $\Delta$ down se situait entre l et $15 \mathrm{mmHg}$ (médiane : $3 \mathrm{mmHg}$ ). La charge volumique $(500 \mathrm{~mL}$ de colloïde pendant $20 \mathrm{~min}$ ) réalisée pendant l'exploration abdominale a significativement réduit le $\Delta$ down $(P=0,001)$ et entraîné des valeurs $\leq 2 \mathrm{mmHg}$ chez les 13 patients. Le $\Delta$ down mesuré immédiatement avant la résection a été plus important chez les patients qui avaient de l'hypotension artérielle (pression artérielle systolique (PAS) $<90 \mathrm{mmHg}$ ) après le retrait de la tumeur que chez les autres patients $[4$ ( I-10) vs I (0-3) $m m H g ; P=0,04]$. Pendant l'hypotension, le $\Delta$ down était plus marqué pour les patients chez qui le remplacement liquidien a restauré la PAS que pour les patients où les liquides ont été inefficaces et les vasopresseurs nécessaires [ $\Delta$ down : 4 (3-9) vs I (I-2) mmHg; $P=0,03]$. Conclusion : Pendant la résection d'un phéochromocytome, un $\Delta$ down $\leq 2 \mathrm{mmHg}$ semble indiquer une déplétion minimale du volume des liquides intravasculaires. Les mesures du $\Delta$ down peuvent guider le remplissage vasculaire utilisé comme prévention et traitement de l'hypotension artérielle suivant la résection d'un phéochromocytome.

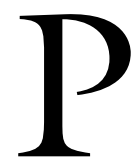

HEOCHROMOCYTOMA surgery is, potentially, associated with significant perioperative morbidity related to overall cardiovascular instability. Favourable outcome requires not only that hypertension and arrhythmia be controlled during surgery, but also that hypotension following tumour resection be treated rapidly. ${ }^{1}$ Such

From the Federation of Anesthesia and Intensive Care, University Hospital, Lille, France.

Address correspondence to: Pr. Benoît Tavernier, Département d'anesthésie réanimation chirurgicale 1, Hôpital Roger Salengro,

CHU de Lille, 59037 Lille cedex, France. Phone: 003204440 74; Fax: 003204449 07; E-mail: btavernier@chru-lille.fr Accepted for publication March 25, 2003.

Revision accepted September 3, 2003. 
hypotension occurs secondary to an immediate decrease in plasma catecholamines, residual effects of antihypertensive drugs, and/or intraoperative fluid and blood loss, and may involve various degrees of alteration in cardiac preload, afterload, and myocardial contractility. Measurements of central venous pressure and pulmonary artery occlusion pressure have thus been proposed to guide treatment, ${ }^{1-5}$ but limitations of such monitoring to estimate cardiac preload as well as to guide volume infusion are now well documented. ${ }^{6}$ In practice, most authors first give fluids and use vasopressive and/or inotropic drugs when arterial pressure is not restored with volume expansion alone. However, large volume fluid administration associated with withdrawal of catecholamines may lead to pulmonary edema, and vasopressors in patients with hypovolemia may be deleterious. ${ }^{1}$

Recent studies have suggested that analysis of the arterial pressure waveform during mechanical ventilation provided reliable estimation of cardiac preload. ${ }^{7-11}$ The arterial systolic pressure variation [the difference between maximal and minimal systolic arterial pressure (SAP) values during one mechanical breath] and its delta down component $(\Delta$ down, = apneic - minimum systolic blood pressure) have been shown to be sensitive indicators of hypovolemia..$^{7-10}$ In anesthetized and mechanically ventilated subjects, a $\Delta$ down $\leq 2 \mathrm{mmHg}$ indicated the absence of hypovolemia, ${ }^{9}$ but only preoperative measurements were reported. The aim of this study was to assess the usefulness of $\Delta$ down measurement for both interpretation and treatment of arterial hypotension following pheochromocytoma resection.

\section{Methods}

\section{Patients and anesthesia}

Thirteen patients (eight males), aged 12-60 yr (median: 33), American Society of Anesthesiologists physical status classes I-III (median: II) scheduled for pheochromocytoma $(n=11)$ or abdominal paraganglioma $(n=2)$ resection were prospectively studied over a period of 18 months. Institutional Research Committee approval was obtained for an observational study. Diagnosis was assessed by both biochemical tests and usual imaging, and then confirmed histologically in all patients. Secreted catecholamines were norepinephrine (NE) in eight patients, epinephrine (E) in one, and a combination of NE, E, and/or dopamine in four. Preoperative preparation was with oral nicardipine (20-150 mg daily) in all patients, as described previously. ${ }^{12}$ On the day of surgery, patients were given $20 \mathrm{mg}$ nicardipine, and $0.5-1.0 \mathrm{mg}$ of alprazolam for premedication. Anesthesia was induced with thiopental (or propofol), sufentanil, and atracurium, and maintained with sufentanil, atracurium, and isoflurane and $50 \%$ nitrous oxide in oxygen. Mechanical ventilation was used with a tidal volume of $8-10 \mathrm{~mL} \cdot \mathrm{kg}^{-1}$ and an inspiratory : expiratory ratio of 1:2. Respiratory rate was adjusted to keep end-tidal $\mathrm{PCO}_{2}$ between 30 and $35 \mathrm{mmHg}$. A nicardipine infusion $\left(1-2 \mu \mathrm{g} \cdot \mathrm{kg}^{-1} \cdot \mathrm{min}^{-1}\right)$ was started following orotracheal intubation, increased during hypertensive crises (up to $7.5 \mu \mathrm{g} \cdot \mathrm{kg}^{-1} \cdot \mathrm{min}^{-1}$ ), and stopped immediately after ligation of the draining vein. In addition, esmolol could be used whenever the heart rate exceeded 110 beats. $\mathrm{min}^{-1}$. According to standard clinical practice in our unit, arterial hypotension following tumour resection (defined by a SAP $<90 \mathrm{mmHg}$ ) was treated with volume loading, and then, if necessary, ephedrine.

\section{Arterial pressure variation}

Following induction of anesthesia, a 20-g radial artery catheter was inserted as part of the routine monitoring for pheochromocytoma surgery. The analogue output from the monitor (Monitor M1165/66A; Hewlett-Packard, Les Ullis, France) was used via an analogue-to-digital converter to record the arterial pressure onto a computer (Toshiba 300 CDS, Tokyo, Japan). Recording and analysis used a customized acquisition software (Bionet 1.2, ITM, Lille University Hospital, Lille, France). The arterial pressure curve was recorded for 20 to $30 \mathrm{sec}$. The value of the SAP during a period of five to ten seconds of endexpiratory pause was used as a reference pressure to measure $\Delta$ down (Figure 1). Pressure waveform analysis was performed off-line with the reviewer unaware of the clinical circumstances at the time of recording. $\Delta$ down was determined during the two or three respiratory cycles that immediately preceded the apnea period. In preliminary experiments, the inter-observer variability in determining the magnitude of $\Delta$ down was $\leq 1 \mathrm{mmHg}$.

\section{Study protocol}

Measurements of $\Delta$ down were made in the following sequence: 1) at the beginning of intervention; 2) before and after "typical" volume loads (i.e., $500 \mathrm{~mL}$ colloid over 15-20 min with no brisk change in arterial pressure or heart rate strongly suggestive of acute catecholamine release, and no change in nicardipine infusion) during abdominal exploration; 3) immediately before ligation of the draining vein; 4 ) at the time of lowest arterial pressure following tumour resection; 5) after volume loading (500-1000 mL colloid), given when $\mathrm{SAP}<90 \mathrm{mmHg}$ following tumour resection; and 6 ) after bolus $i v$ injection of ephedrine, 

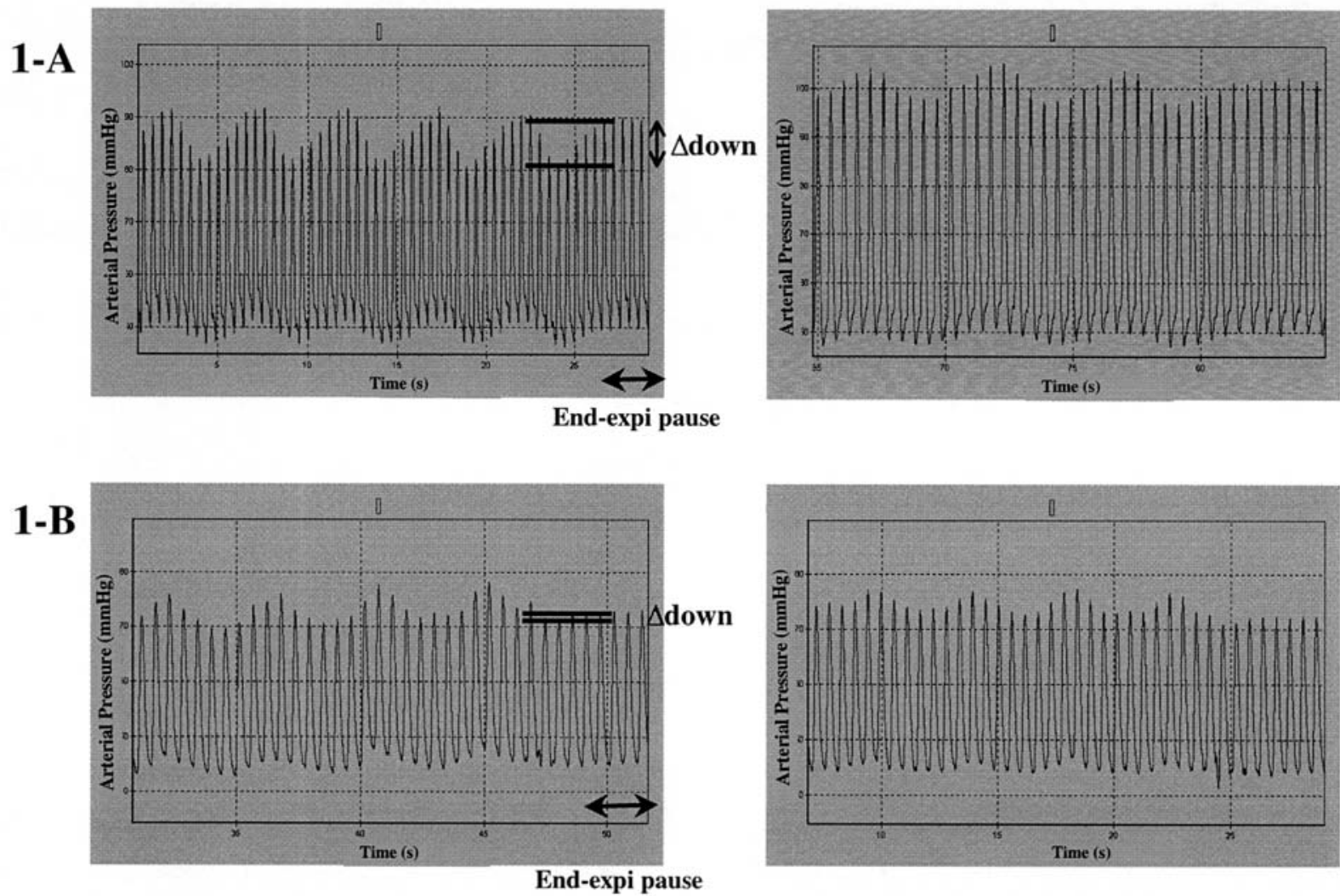

FIGURE 1 Systemic arterial pressure curves recorded in two patients after tumour removal (left panel) and following fluid administration with $500 \mathrm{~mL}$ colloid (right panel). The difference between the systolic arterial pressure (SAP) during end-expiratory pause (end of recording) and the minimum SAP defines $\Delta$ down. Figure lA: initial $\Delta$ down $=9 \mathrm{mmHg}$. Fluid loading reduces $\Delta$ down and increases the SAP. Figure 1B: $\Delta$ down $=1 \mathrm{mmHg}$. Fluid loading has no effect on either $\Delta$ down or SAP.

in case of ineffectual fluid replacement (defined as the absence of restoration of $\mathrm{SAP} \geq 90 \mathrm{mmHg}$ following volume load). SAP, heart rate, tidal volume and airway pressures were recorded simultaneously with each measure of $\Delta$ down. Respiratory variables were obtained from the ventilator monitoring panel, and quasi-static respiratory compliance was calculated according to standard equation.

\section{Analysis}

Results are expressed as median and range. The changes in $\Delta$ down, SAP, and heart rate induced by "typical" volume loads during abdominal exploration as well as by tumour resection were assessed using Wilcoxon's rank sum test. The values of $\Delta$ down measured immediately before ligation of the draining vein were analyzed according to the incidence of arterial hypotension ( $\mathrm{SAP}<90 \mathrm{mmHg}$ ) following tumour resection (Mann-Whitney test). Then, the $\Delta$ down values measured following tumour resection were analyzed according to the effectiveness of subsequent volume loading (restoration of SAP $\geq 90 \mathrm{mmHg}$; Mann-Whitney test). Finally, Spearman coefficient was used to assess correlation between changes in SAP and $\Delta$ down during tumour removal. A $P$ value $<0.05$ was considered significant.

\section{Results}

Eleven patients had a laparotomy and two a laparoscopy. Duration of intervention was $200 \mathrm{~min}$ (120-300). The total intraoperative dose of nicardipine was $18 \mathrm{mg}(6-35)$. Three patients received esmolol, and total volume of fluids (cristalloids and colloids) was $2850 \mathrm{~mL}(2000-5200)$. No patient had a peak SAP above $220 \mathrm{mmHg}$ throughout anesthesia. 


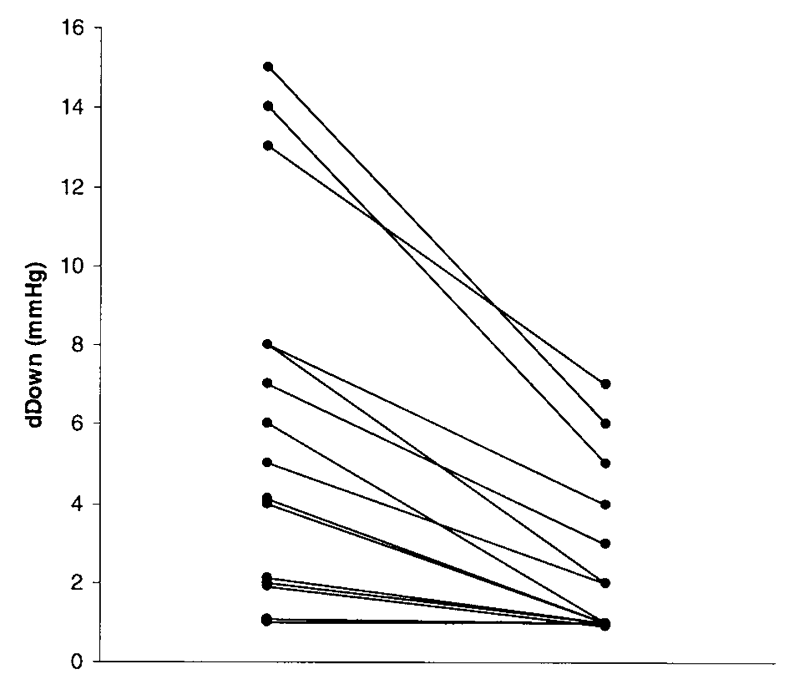

FIGURE $2 \Delta$ down values measured before and after volume loads $(n=15)$ of $500 \mathrm{~mL}$ colloid performed in ten patients during abdominal exploration for pheochromocytoma surgery. The $\Delta$ down is reduced following fluid loading $(P=0.001)$.

\section{Initial $\Delta$ down and effect of volume loading}

$\Delta$ down ranged between 1 and $15 \mathrm{mmHg}$ (median: 3 $\mathrm{mmHg}$ ) at the beginning of abdominal exploration. At that time, tidal volume and quasi-static respiratory compliance were $640 \mathrm{~mL}(410-850)$ and $49 \mathrm{~mL} \cdot \mathrm{cm}$ $\mathrm{H}_{2} \mathrm{O}^{-1}(22-75)$, respectively. During abdominal exploration, 15 volume loads $(500 \mathrm{~mL}$ of colloid) were performed in ten patients. At that time, nicardipine was infused at a rate of $1.4 \mu \mathrm{g} \cdot \mathrm{kg}^{-1} \cdot \mathrm{min}^{-1}(0.5-5)$. As shown in Figure 2, fluid loading reduced $\Delta$ down $(P$ $=0.001)$, whereas no significant changes in SAP [from $102 \mathrm{mmHg}(70-127)$ to $112 \mathrm{mmHg}(74-153) ; P=$ 0.11 ] and heart rate [from 99 beats. $\mathrm{min}^{-1}(55-122)$ to 97 beats. $\mathrm{min}^{-1}(51-124) ; P=0.59$ ] were observed. In addition, repeated measurements showed that following $500 \mathrm{~mL}$ of additional colloid in five patients, $\Delta$ down was $\leq 2 \mathrm{mmHg}$ in all 13 patients.

\section{$\triangle$ down and SAP following tumour resection}

Tumour removal decreased SAP from 125 (76-163) to $88(65-130) \mathrm{mmHg}(P=0.004)$, while $\Delta$ down did not change significantly [from $2(0-10)$ to 2 (1-9) $\mathrm{mmHg} ; P=0.62]$. There was no correlation between the individual variations in SAP and $\Delta$ down (rho $=$ $0.13 ; P=0.60)$. Arterial hypotension $(\mathrm{SAP}<90$ $\mathrm{mmHg}$ ) occurred in five out of 11 patients who had a $\mathrm{SAP} \geq 90 \mathrm{mmHg}$ immediately before ligation of the draining vein. In these patients, the $\Delta$ down measured before resection was larger than in patients in whom arterial hypotension did not occur [4 (1-10) vs 1 $(0-3) \mathrm{mmHg} ; P=0.04]$.

Two patients had a SAP $<90 \mathrm{mmHg}$ just before and following ligation of the draining vein. Thus, a total of seven patients were hypotensive after tumour resection. At that time, $\Delta$ down was greater in the four patients where volume loading $(500 \mathrm{~mL}$ colloid) restored arterial pressure (Figure 1A) than in the three remaining patients where SAP did not change following fluid replacement $(500-1000 \mathrm{~mL}$; Figure 1B) but responded to ephedrine [6-9 $\mathrm{mg} ; \Delta$ down: 4 (3-9) vs $1(0-2) \mathrm{mmHg} ; P=0.03]$.

\section{Discussion}

This study was undertaken to assess the usefulness of $\Delta$ down measurements during pheochromocytoma surgery. The results suggest that even during continuous infusion of nicardipine or large changes in blood catecholamine concentration, fluid loading reduces $\Delta$ down to the same values as those previously reported in anesthetized normal patients. ${ }^{9}$ During tumour removal, the stability of $\Delta$ down and the absence of correlation between changes in SAP and $\Delta$ down strongly suggest that reduced cardiac preload is not a major mechanism of the reduction in arterial pressure characteristics of pheochromocytoma resection. However, that $\Delta$ down before resection was larger in patients where SAP decreased to less than $90 \mathrm{mmHg}$ suggests that the occurrence of arterial hypotension is favoured by pre-existing reduced cardiac preload. Thus, $\Delta$ down measurements before tumour resection may contribute to predict arterial hypotension after tumour removal. Finally, $\Delta$ down measured at the time of lowest arterial pressure could be used to guide fluid therapy, in accordance with previous studies performed in other conditions. ${ }^{8-10}$

During abdominal exploration, $\Delta$ down varied widely, but fluid expansion resulted in a $\Delta$ down of 2 $\mathrm{mmHg}$ or less in all patients. These results are very similar to those obtained in anesthetized and mechanically ventilated subjects during graded hemorrhage and subsequent volume replacement. ${ }^{9}$ In that study, $\Delta$ down was smaller after hetastarch than at baseline, and a $\Delta$ down $\leq 2 \mathrm{mmHg}$ appeared to indicate the absence of hypovolemia. Both studies thus suggest that a $\Delta$ down $\leq 2 \mathrm{mmHg}$ may constitute a reasonable end-point to ensure minimal intravascular volume depletion in anesthetized patients. Our results, however, extend the former observations to patients receiving nicardipine in various dosages, before and following pheochromocytoma resection, and suggest 
that large and rapid changes in systemic vascular resistance do not alter the value of $\Delta$ down for the assessment of cardiac preload.

Our results suggest that a small $\Delta$ down before ligation of the draining vein may reduce the risk of arterial hypotension following tumour removal. This is consistent with previous studies indicating that adequate fluid resuscitation is important for the prevention of severe hypotension at this stage of pheochromocytoma surgery. ${ }^{1,5,13}$ However, the values measured at that time in patients in whom arterial hypotension occurred after tumour removal overlapped those measured in other patients. This underlines that the predominant mechanism of severe hypotension following tumour resection appears to be a sharp decrease in arterial tone, and that severe hypotension may still occur in patients without preexisting hypovolemia. Accordingly, the $\Delta$ down did not change during tumour removal in this study, and the sole patient who presented a hypotensive episode with $\mathrm{SAP}<70 \mathrm{mmHg}$ had a $\Delta$ down of $1 \mathrm{mmHg}$ before and after tumour ablation.

Seven patients in this study had an episode of hypotension after tumour removal. This apparently high incidence is explained by the fact that we chose a SAP of $<90 \mathrm{mmHg}$ to define hypotension. In fact, severe hypotension, as defined by a SAP $<70 \mathrm{mmHg}$, was observed in only one patient. Nevertheless, our results suggest that $\Delta$ down measurements may adequately guide fluid resuscitation after tumour resection. Previous studies have shown that the main value of $\Delta$ down is to predict the response of cardiac output to fluid loading, but in patients with hypovolemia, the response to fluid therapy is usually an increase in both cardiac output and arterial pressure. ${ }^{10}$ Therefore it appears reasonable to propose that, when treating arterial hypotension following pheochromocytoma resection, a large $\Delta$ down indicates that fluid should be given, whereas a small $\Delta$ down $(\leq 2 \mathrm{mmHg})$ strongly suggests that fluid resuscitation is no longer necessary and may be deleterious. In this case, vasopressors and/or inotropic agents should be used.

Several limitations must be discussed. First, as in many studies concerning pheochromocytoma surgery, the number of patients included was small, and although statistically significant differences were observed, the predictive value of $\Delta$ down measurements before and during tumour removal could not be established. Second, simultaneous measurements of other indexes, such as central venous pressure, pulmonary artery occlusion pressure, or left ventricular end diastolic area measured by transesophageal echocardiography may have allowed to study the cor- relation of $\Delta$ down with these indexes of volume status or ventricular preload. However, because several recent studies have shown that these variables are not reliable indicators of fluid responsiveness, ${ }^{6,14}$ we did not systematically measure them in our patients. The clinical relevance of our results may be questioned, since patients do not systematically exhibit severe and/or prolonged hypotension following pheochromocytoma removal. However, clinical experience and the literature show that hypotensive episodes requiring rapid treatment are not unusual and inadequate treatment may be deleterious in such circumstances. ${ }^{1,15-17}$ Finally, while a specific software was used for off-line data analysis in our study, it should be noted that, in clinical practice, $\Delta$ down can be measured with most monitors directly from the arterial pressure trace ${ }^{18}$ or, after identification of the systemic arterial pressure as a pulmonary artery pressure, by using the "wedge measurement" procedure. ${ }^{19}$

In conclusion, the present study suggests that a $\Delta$ down $\leq 2 \mathrm{mmHg}$, which has been proposed to define the absence of hypovolemia in anesthetized patients, can also be used in the particular conditions of pheochromocytoma surgery. Maintaining $\Delta$ down at such small values may contribute to reduce the risk of severe arterial hypotension following tumour removal. In addition, $\Delta$ down measurements allow to guide volume resuscitation and avoid unnecessary fluids when treating arterial hypotension after tumour resection. Since invasive monitoring of arterial pressure is routinely used during pheochromocytoma surgery, our study suggests that measurement of $\Delta$ down could be performed systematically in these patients.

\section{References}

1 Desmonts JM, Le Houelleur J, Remond P, Duvaldestin $P$. Anaesthetic management of patients with phaeochromocytoma. A review of 102 cases. Br J Anaesth 1977; 49: 991-8.

2 Roizen MF. Anesthetic implications of concurrent diseases. In: Miller RD (Ed.). Anesthesia. New York: Churchill Livingstone Inc.; 1994: 903-1014.

$3 \mathrm{Mihm}$ FG. Pulmonary artery pressure monitoring in patients with pheochromocytoma. Anesth Analg 1983; 62: 1129-33.

4 Pinand M, Desjars P, Tasseau F, Cozian A. Preoperative acute volume loading in patients with pheochromocytoma. Crit Care Med 1985; 13: 460-3.

5 Hull CJ. Phaeochromocytoma. Diagnosis, preoperative preparation and anaesthetic management. Br J Anaesth 1986; 58: 1453-68.

6 Michard F, Teboul JL. Using heart-lung interactions to assess fluid responsiveness during mechanical ventila- 
tion. Crit Care 2000; 4: 282-9.

7 Perel A, Pizov R, Cotev S. Systolic blood pressure variation is a sensitive indicator of hypovolemia in ventilated dogs subjected to graded hemorrhage. Anesthesiology 1987; 67: 498-502.

8 Coriat P, Vrillon M, Perel A, et al. A comparison of systolic blood pressure variations and echocardiographic estimates of end-diastolic left ventricular size in patients after aortic surgery. Anesth Analg 1994; 78: 46-53.

9 Rooke GA, Schwid HA, Shapira $\Upsilon$. The effect of graded hemorrhage and intravascular volume replacement on systolic pressure variation in humans during mechanical and spontaneous ventilation. Anesth Analg 1995; 80: 925-32.

10 Tavernier B, Makhotine O, Lebuffe G, Dupont J, Scherpereel $P$. Systolic pressure variation as a guide to fluid therapy in patients with sepsis-induced hypotension. Anesthesiology 1998; 89: 1313-21.

11 Michard F, Boussat S, Chemla D, et al. Relation between respiratory changes in arterial pulse pressure and fluid responsiveness in septic patients with acute circulatory failure. Am J Respir Crit Care Med 2000; 162: 134-8.

12 Proye C, Thevenin D, Cecat P, et al. Exclusive use of calcium channel blockers in preoperative and intraoperative control of pheochromocytomas: hemodynamics and free catecholamine assays in ten consecutive patients. Surgery 1989; 106: 1149-54.

13 Bravo EL, Gifford RW Jr. Pheochromocytoma: diagnosis, localization and management. N Engl J Med 1984; 311: 1298-303.

14 Pinsky MR. Functional hemodynamic monitoring. Intensive Care Med 2002; 28: 386-8.

15 Shupak RC. Difficult anesthetic management during pheochromocytoma surgery. J Clin Anesth 1999; 11 : 247-50.

16 Kinney MA, Warner ME, vanHeerden JA, et al. Perianesthetic risks and outcomes of pheochromocytoma and paraganglioma resection. Anesth Analg 2000; 91: 1118-23.

17 Prys-Roberts C. Phaeochromocytoma-recent progress in its management. Br J Anaesth 2000; 85: 44-57.

18 Stoneham MD. Less is more...using systolic pressure variation to assess hypovolaemia (Editorial). Br J Anaesth 1999; 83: 550-1.

19 Tavernier B. Evaluation peropératoire de la volémie. In: Société Française d'Anesthésie et de Réanimation (Ed.). Conférences d'Actualisation, Paris: Editions scientifiques et médicales Elsevier SAS et SFAR; 2001: 385-98. 